\title{
The Application and Prospect of 3D Printing and $V R$ in Educational Innovation
}

\author{
Yu-Jie Dai* \\ College of Biotechnology \\ Tianjin University of Science and Technology \\ Tianjin, China \\ yjdai@126.com
}

\author{
Qing-Yuan Hua \\ College of Biotechnology \\ Tianjin University of Science and Technology \\ Tianjin, China
}

\begin{abstract}
With the rapid development of 3D printing and virtual reality (VR) technology, they have been used in many fields, but they have just started in the field of education. Aimed at this problem, this paper introduces the principles and characteristics of 3D printing and VR technology, and illustrates related theoretical research and application in the field of education. It is suggested that scholars should speed up the research and development of the new technology and enhance their popularity. The related technology enterprises should increase the technical publicity work and provide professional training of 3D printing and VR technology. The multi-function virtual experiment teaching platform should be constructed and perfected as soon as possible. The application of $3 \mathrm{D}$ printing and VR technologies in education can accelerate the process of educational innovation, so as to achieve common progress for science, technology and education.
\end{abstract}

Keywords-educational innovation; $3 D$ printing technology; $V R$; virtual experiment teaching platform

\section{INTRODUCTION}

The 21st century is the era of information technology, and the times of rapid development of new technologies. More and more people recognize the importance of educational innovation for national development and personnel training. In recent years, China has repeatedly proposed to build an innovative country and to cultivate innovative talents. But the cultivation of talent is inseparable from education. Thus education innovation has its necessity and urgency. With the development of new technology, many scholars have carried out a lot of research on educational innovation, including education mode, educational content, educational environment and educational means. There are two research goals: First, Cutting-edge technology is applied to the education industry, making the school students can understand the latest new technology development. Second, cultivating students' innovative and manual operation ability, and promoting the rapid development and transformation of China's education[1].This research mainly analyzed the 3D printing and VR technologies developed in recent years, also the application and prospect of these technologies in educational innovation were introduced.

This work was supported by the National Natural Science Foundation of China (Grant No. 21272171)

\section{APPLICATION OF NEW TECHNOLOGY IN EDUCATIONAL INNOVATION}

\section{A. 3D printing technology}

\section{1) Introduction of $3 D$ printing technology}

$3 \mathrm{D}$ printing is a rapid prototyping (RP) technology that constructs physical objects in three-dimensional form. The principle is that solid model is divided into a number of thin layers first, and then a thin layer of solid materials is generated at the time of printing. Finally, layers of objects formed through the plastic or powder metal and other adhesive materials. This has become the main form of the current Additive Manufacturing (AM) technology. The production process is divided into two stages of design and printing, as shown in Fig. 1.

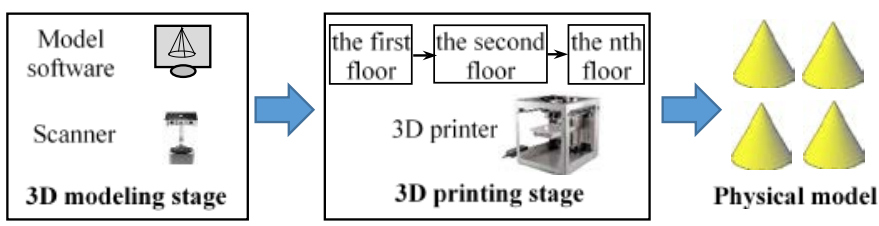

Fig. 1. The basic process of 3D printing

The most prominent advantage of 3D printing technology is that mechanical processing or any mold is not necessary, it can be generated from any shape objects directly from computer graphics data. Compared with the traditional technology, 3D printing technology can be personalized production, the user can design required model through the modeling software to meet the needs of designers. The traditional technology in the mold making process can be left out, which shortens the product development cycle and reduce costs greatly.

2) The Application of $3 D$ Printing Technology in Educational Innovation

As a new type of rapid prototyping and rapid manufacturing technology, 3D printing technology attracts more and more people's attention. Now it has been integrated into the aerospace, automobile manufacturing, food, education, medicine and other fields, and is favored by the majority of scholars [2]. Many scholars have done a lot of research in the field of education, including theory development, teaching 
mode, application and so on, which favors the 3D printing technology quickly integrating into the education innovation.

a) The theoretical basis of the 3D printing technology's application in the education and teaching.

Learning theory is one of the core and most mature areas of psychology. Whether Watson's behavioral learning theory, or Skinner's Operant Conditioning theory [3], can effectively guide the 3D printing technology in teaching practice.

The experimental teaching method in the teaching theory makes the 3D printing technology have full use in the field. Experimental method is a knowledge acquisition method that the students can operate the instrument independently under the guidance of the teacher and observe the phenomena and results caused by these operations.

Dale's "cone of experience" theory [4] is one of the important theoretical bases for the research on the effects of teaching media. It divides people's experiences into three modes: enactive, iconic and symbolic modes. The 3D printing can better show the integration of three levels of experiences, which helps learners acquire learning experience and cognitive experience, promote learners to acquire and understand knowledge in three dimensions, and expand creative thinking to improve learning outcomes.

b) The application of $3 D$ printing technology in teaching mode.

In recent years, there are some investigation and exploration in the application of 3D printing technology in the STEM courses in order to promote technology-driven innovation in education, which can combine technical engineering education with artistic humanities education as a part of school culture, and it is also known as STEAM Education. The 3D Printing Curriculum is a typical STEAM learning resource package for the promotion of technical and engineering education in the field of vocational education. The STEAMtrax curriculum model is a teaching model which based on the problem-inquiry. The independent research and hands-on learning opportunities can be provided through the theme of the story design with the aid of Hands-on Science Kits enhancing 3D design and printing in order to obtain the core scientific theoretical knowledge and application skills.

Solid Learning is a new teaching model based on 3D printing technology. It refers to the integration of rapid prototyping and digital manufacturing technology in education, providing teachers and students with downloadable resource object files that can be used to create physical prototypes directly through the 3D printing system.

\section{c) The application projects.}

The representative educational application projects can be divided into three categories, including the creative customer space, innovation laboratory and STEAM courses [5]. The UK Ministry of Education has launched a one-year pilot project, which took 21 schools as pilots. In which 3D printing technology was applied to the courses of mathematics, physics, computer science and engineering design, so as to extend the applications of 3D printing in teaching and promote education innovation. Glen Bull and his team of the University of
Virginia created a curriculum called "Learning by doing"[6] Many national public libraries in different countries teach the usage methods of $3 \mathrm{D}$ printing to different social groups with different education levels, even offer guidance in relevant design and manufacturing. Some university libraries offer 3D printing to teachers and students to support the daily teaching and research activities. 3D print technology has been introduced into the basic education in Shanghai of China. Also regular courses are opened and some services such as 3D design and computer aided manufacturing are offered for interested students to print their own designs.

\section{B. VR technology}

\section{1) Introduction of VR technology}

Virtual Reality (VR) technology offers a virtual environment integrating realistic visual, auditory and tactile features by combining multimedia technology with simulation technology. As shown in Fig. 2, the user interacts with the object in the virtual environment in a natural way to produce an immersive feelings and experiences. The basic connotation of virtual reality technology includes: First, the operator can interact with the virtual environment through human natural activity. Second, the virtual entity is not an objective reality, and it is generated by the computer through the corresponding algorithm. Third, the interaction between virtual and reality needs and relies on specialized sensing equipment.

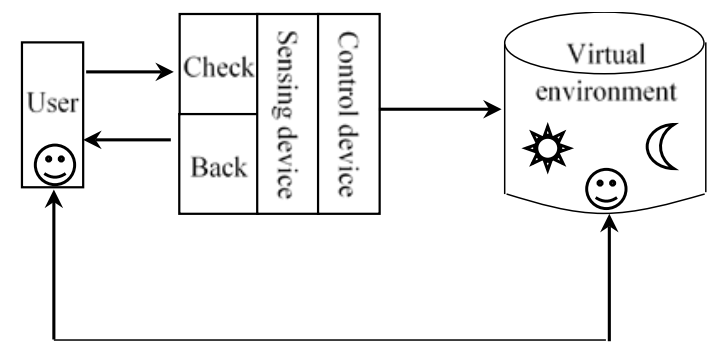

Fig. 2. The model diagram of virtual reality system

The main features of VR technology are as follows: Immersion - with the aid of computers, sensors and image generation system, VR gives a virtual reality environment based on human visual and auditory physiological and psychological characteristics, so that participants have immersive feeling. Interactivity - Mainly refers to the realization of human interaction with objects in the virtual environment, so that participants interact with the computer using natural means and behavior to achieve true man-machine harmony. Imagination - mainly refers to the realization of $3 \mathrm{D}$ display of real scenes on the basis of computer graphics. VR technology can be divided into desktop, enhanced, immersive and distributed virtual reality according to the different characteristics of the media. It can also be divided into immersion pattern, simple pattern and shared pattern based on their different functions

2) The Application of VR technology in Educational Innovation

In the past 10 years, VR technology has developed rapidly in China because of its operability, authenticity and repeatability. Its application is very broad, and in the field of 
education, "virtual laboratory", "virtual teaching" and other new educational methods have emerged [7]. These methods are the embodiment of educational informationization and educational modernization, and also the display of high-tech level of education. Therefore, many scholars have carried out a lot of theoretical and experimental research on how to apply VR technology and related thoughts to education and teaching. It mainly focuses on the aspects of theory, educational application and the influence of VR technology on educational innovation.

a) The theoretical basis of the VR technology's application in the education and teaching.

According to the situated cognition theory, knowledge is interactive with action and it is contextualized. Knowledge develops forward through activities. It is better to organize teaching in a real situation, in a way that is similar to human practice, and to combine acquired knowledge with learner's development, identity construction, and so forth. The interaction and the verisimilitude of the virtual environment are conforming to the view of situational cognition.

Constructivism theory [8] believes that knowledge is not taught through the teachers, but acquired by the learners in a certain situation with the help of others, using the necessary learning materials, through the way of meaning construction. The virtual cultural background and virtual textbook content speed up the learner's learning process, reducing the teaching pressure on teachers.

According to Brunner's discovery learning theory [9], students are an active researcher in the teaching process, and the role of teachers is to form a situation in which students can independently explore rather than provide ready-made knowledge. In the virtual environment created by VR, students can acquire knowledge and form their own cognitive systems by interacting with the surroundings.

These theories provide the theoretical guidance for the application of VR technology in education and teaching. VR scene teaching has the characteristics as follows: more vivid content, more interactive teaching process, the wider scope of knowledge dissemination, more autonomy and better achieve individualized teaching for students to choose.

\section{b) Educational applications}

The application of VR technology in education mainly focuses on the experimental teaching and distance education [10].

The United States is the most advanced country in VR technology, which first uses VR technology in teaching. The software of Virtual Reality in Chemical Engineering Laboratories developed by Michigan State University in the U. $\mathrm{S}$ is an application of VR technology in chemical engineering. With the software, a virtual modern chemical plant can be built to allow students to operate in a $3 \mathrm{D}$ virtual scene, to observe and experience chemical reactions at close range. The Chemistry Collective package developed by Carnegie Mellon University allows the experimenter to connect the virtual lab and operate the experimental equipment remotely. The experimental data are analyzed by software, and the results are fed back to the connector. The MIT's i-Lab service give a share of virtual online experiment resources over the internet to provide students with a platform for virtual experimentation. In addition, China attaches great importance to VR technology research and development, and made great achievements in medical practice, economic management, marketing and so on.

\section{THE DEVELOPMENT DIRECTION OF NEW TECHNOLOGY IN EDUCATIONAL INNOVATION}

\section{A. Speed up the research and development of the new technology and enhance their popularity}

Although 3D printing technology and VR technology have developed and applied to various fields rapidly in recent years, there are few specialized application modules for these technologies, which confine the popularity of these technologies. It is particularly important to speed up the research process and increase the professional modules in the technical education field.

\section{B. Increase technical publicity, provide professional training}

At present, 3D printing and VR technologies are not widely used in primary and secondary schools even in most universities. Teachers and students lack of professional trainings. There are many problems in the application of these technologies, which hinders the promotion of technology. Therefore, on the one hand it is necessary to increase investment in technology publicity, so that teachers and students can access these cutting-edge technologies in time, and understand its advantages and disadvantages in order to apply the technology properly. On the other hand, the school can offer relevant technical courses and conduct theoretical and practical training for teachers and students, so as to train scientific and technological talents, and provide relevant professional talents to the $\mathrm{R} \& \mathrm{D}$ department.

\section{Constructing Multi - functional Virtual Experiment Teaching Platform.}

The multi-functional virtual experimental teaching platform should be constructed by using virtual technologies such as 3D printing and VR. The development and improvement of virtual technology in education should be applied to form a virtual teaching system. This platform integrates experiment and teaching to provide the corresponding virtual environment for students at different stages. In the primary and secondary school, it focuses on teaching knowledge and inspiring students. For this purpose, the platform can create virtual classroom for students, integrate textbook knowledge into the environment. The level teaching can be used to arouse students' interest in learning by themselves. 3D printing and VR can be used to give the unimaginable scenes in physics and mathematics, so as to facilitate understanding and deepen the knowledge memory of students. In the university students, the platform of the virtual laboratory and virtual classroom can reduce the experimental risk and cost, ensuring the safety of students and researchers.

\section{CONCLUSION}

With the development of science and technology, 3D printing and VR technology will develop in the direction of 
precision, intelligence, generalization and convenience, which provides technical support for further application in education.

In the future, we should make the most of the characteristics and advantages of virtual technology, and focus on strengthening and improving the popularization and application of 3D printing and VR technologies in the field of education. It is necessary to build a multi-functional virtual experimental teaching platform. Through the application of virtual technology in education, the social value of technology itself can be reflected and improved. The process of educational innovation can be accelerated. The goal of codevelopment of education and new technology can be achieved.

\section{ACKNOWLEDGMENT}

This work was supported by the National Natural Science Foundation of China (Grant No. 21272171)

\section{REFERENCES}

[1] GL Pierce , PF Cleary, "The K-12 educational technology value chain: Apps for kids, tools for teachers and levers for reform," Education \& Information Technologies, vol. 21, pp. 863-880, July 2016.

[2] Leukers, B., Gülkan, H., Irsen, S. H., et al, “ Hydroxyapatite scaffolds for bone tissue engineering made by 3D printing,” Journal of Materials Science Materials in Medicine, vol. 16, pp. 1121-1124, December 2005.
[3] S Dymond, D O'Hora, R Whelan, et al, "Citation Analysis of Skinner's Verbal Behavior : 1984-2004,” Behavior Analyst, vol. 29, pp. 75-88, April 2006.

[4] Seels B, "The Relationship of Media and ISD Theory: The Unrealized Promise of Dale's Cone of Experience,” Proceedings of selected research and development presentations at the 1997 National Convention of Association for Educational Communications and Technology, vol. 1, pp. 357-361,1997.

[5] NW Sochacka, KW Guyotte , J Walther, et al, "Faculty reflections on a STEAM-inspired interdisciplinary studio course,” Asee Conference \& Exposition , January 2013.

[6] Bull G, Garofalo J, “Learning by Remixing,” Learning \& Leading with Technology, vol. 35, pp. 10, May 2008.

[7] Giese B, Koenigstein S, Wigger H, et al, "The Application of Virtual Reality Technology in Teaching of Industrial Design - Outline of the Project for the Human-Computer Interactive Simulation of the Upper Limb Operations,” Applied Mechanics \& Materials, vol. 464, pp. 420423, November 2013.

[8] AF Brandon , AC All, "Constructivism theory analysis and application to curricula,” Nurs Educ Perspect , vol. 31, pp. 89-92, March 2010.

[9] M Costello, "The benefits of active learning: Applying Brunner's discovery theory to the classroom: Teaching clinical decision-making to senior nursing students," Teaching \& Learning in Nursing, vol. 12, pp. 212-213, July 2017.

[10] Barbara A. Sommer, Robert Sommer, “A Virtual Lab in Research Methods,” Teaching of Psychology, vol. 30, pp. 143-147, 2003. 